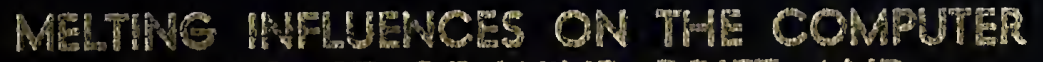
FORECAST OI WINO DRIFT AND CONCENTRATION OF SEA ICE

\author{
KaNNETH M. ARVINE
}



This document has been approved for publio release and Salo; ito dist. 

6 

MELTING INFLUENCES ON THE COMPUTER

\section{FORECAST OF WIND DRIFT AND CONCENTRATION \\ OF SEA ICE}

$* * * * *$

Kenneth $M$. Irvine 



\title{
MELTING INFLUENCES ON THE COMPUTER FORECAST OF WIND DRIFT AND CONCENTRATION OF SEA ICE
}

\author{
by \\ Kenneth $M$. Irvine
}

Lieutenant, United States Navy

Submitted in partial fulfillment of the requirements for the degree of

MASTER OF SCIENCE

United States Naval Postgraduate School

Monterey, California

1965 
NYS AROHIVE

1965

YKUINE, K. 
MELTING INFLUENCES ON THE COMPUTER

FORECAST OF WIND DRIFT AND CONCENTRATION

OF SEA ICE

$$
\begin{gathered}
\text { by } \\
\text { Kenneth M. Irvine }
\end{gathered}
$$

This work is accepted as fulfilling

the thesis requirements for the degree of

MASTER OF SCIENCE

from the

United States Naval Postgraduate School 



\section{ABSTRACT}

Knodle has developed a computer program to provide five-day forecasts of the wind drift and concentration of sea-ice[l]. One of the problems not considered in the program is the effect of melting. Melting influences concentration in two ways. It reduces the amount of ice directly, and changes in thickness and concentration change the wind drift. A model to describe how ice-melt decreases thickness and concentration is developed and programmed. The results are used to modify the input data in Knodle's wind drift forecast;foreoasts are compared with those based on wind drift alone. The modification enhances the use of the program as a forecast tool with the addition of normally avallable data. 

TABLE OF CONTENTS

Section

Title

Page

1.

Introduction

1

2. Models for the melting effects

3

3.

Developemenț of computational equations

6

4. Programming technique

5.

Results

16

6.

Limitations and error analysis

22

7. Recommendations

29

8.

Conclusions

30

9.

Bibliography

31

Appendix A

32

Appendix B

38 


\section{LIST OF ILLUSTRATIONS}

Figure

Pago

1.

Heat of fusion vs. salinity

2.

Forecast concentration 15 June,1953 19

3.

Forecast concentration 17 May,1959 20

4.

Forecast concentration 8 June, 195721 

1. Introduction

A sea-ice forecast that is accurate and timely has assumed increasing importance as operations in the Arctic areas increase. Reconnaissance and commercial flights, basic research, submarine operations, exploration, and resupply operations are all safer,more economical, and efficient if strategic and tactical commanders or project managers have available accurate forecasts.

In several areas of meteorological analysis and forecasting the large, high-speed digital computer has become a valuable aid. The results, notably in some upper-air weather charts, are as good, if not better, than those produced by slower subjective means. Significant steps in the programing of oceanographic forecasts have been taken and show promise. Machine methods of predicting sea-ice represent an improvement over other techniques in that 1) results are immediately available for large areas once inputs are made, 2)retention of computed values and ease of modification enhance the continuity of the forecast, 3) once the program is operating relatively little skill is required to produce the forecast, 4) at least some idea of the sea-ice behavior is available for areas not frequently observed.

There are some disadvantages to computer methods, among them: 1)putting observations into digital form may be difficult and time consuming; 2)grid size limits the treatment of important details; 3)errors introduced by finite approximations may lead to instabilities. 
Knodle in 1964 proposed and tested a digital model to give five-day forecasts of the wind drift and concentration of sea-ice[I]. Lacking in Knodle's model is consideration of melting, which he feels is a major source of error. Melting changes both the thickness and the concentration, upon which depends the wind drift.

Another influence on drift, not considered in the Knodle program,nor in the one proposed here, is that of currents. Little is known of the currents in Baffin Bay, the area for which this work was done, as most measurements were taken in ice-free regions,late in the summer season. Results of program forecasts show areas where it appears very likely that errors due to current effects are important.

This paper will present a model of the melting effects and incorporate it into the wind drift program. Then the results of this modified program are compared to the original forecast to see if melting indeed contributes significantly to forecast accuracy. 

2. Models for the melting effects

Melting of sea-ice may be separated into three major processes; thickness reduction, concentration reduction, and puddling of the ice surface. Each process may now be considered separately. Zubov has proposed mathematical models for the first two processes, while a modification of the concentration reduction leads to an expression for the puddling effect [2].

The first item to consider is the thickness reduction model. For this Zubov makes the assumptions that there exists a flat,uniform ice field, the amount of incoming radiation remains unchanged for the period of time under consideration, and the ability of the ice to absorb heat increases proportionally with time. Further, he assumes that all the heat absorbed by the ice is used to reduce the thickness. Equation (I) follows from these assumptions.

$$
h^{\prime}=\frac{b T^{2}}{2 p_{i} \lambda}
$$

where $h^{\prime}=$ thickness of ice melted $(\mathrm{cm})$

$$
\begin{aligned}
\mathrm{bT}= & \text { coefficient of heat absorption } \\
& \text { (cal/cm -day) } \\
P_{i}= & \text { ice density }\left(\mathrm{gm} / \mathrm{cm}^{3}\right) \\
\lambda= & \text { heat of fusion }(\mathrm{cal} / \mathrm{gm}) \\
T= & \text { time for which reduction } \\
& \text { is to be computed (day) }
\end{aligned}
$$

In this equation the constant $b$ is to be evaluated by empirical means. 
Next consider the process of concentration reduction. In ice areas of less than 10/10 coverage some heat will be absorbed by the water. Zubov proposes that this heat alone is used to reduce the area of the adjacent floes, and that It is entrely used in this process. This seems reasonable considering the albedos of the two surfaces and the low water temperatures near the ice while melting is in progress. The heat is transmitted to the ice by mechanical mixing caused by winds, tides, and currents, and by thermo-haline convection. The resulting equation is expressed by Zubov in terms of the ice-free water concentration.

$$
\begin{aligned}
w_{t} & =w_{0} e^{\frac{m T}{h p_{i} \lambda}} \\
\text { where } w_{t} & =\text { area of ice-free water (tenth) } \\
w_{0} & =\text { original ice-free area (tenth) } \\
m^{0} & =\text { heat absorbed (cal/cm day) } \\
h & =\text { ice thickness }(\mathrm{cm}) \\
P_{L} & =\text { ice density }\left(\mathrm{gm} / \mathrm{cm}^{3}\right) \\
\lambda & =\text { heat of fusion }(\mathrm{cal} / \mathrm{gm}) \\
T & =\text { time for which reduction is to } \\
& \text { be computed (day) }
\end{aligned}
$$

The last effect considered is that due to puddling on the ice surface. The necessity for this, or some like expression, is seen by examination of equation (2), which does not apply in situations of $10 / 10$ ice coverage. It was felt that it would be unrealistic to assume that areas of total coverage would remain throughout the season. 
4

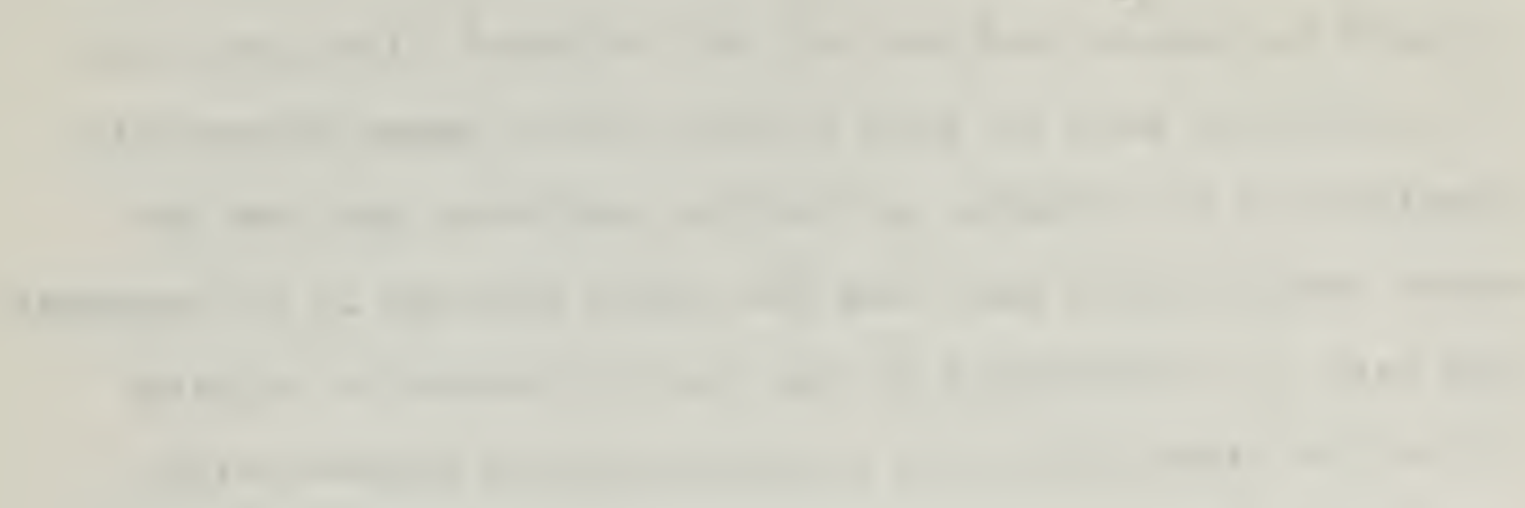

1 n t 
Thus, a mechanism was required which would reduce the areas of total coverage as the season progressed. Puddling of the ice surface seemed to provide an answer. If a puddle of specified area is heated, the heat absorbed will increase the area of the puddle and.its depth. The depth increase results in a reduction of the thickness of the ice layer below the puddle. Since the puddle absorbs more heat than the surrounding ice, this thickness decrease should proceed at a faster pace than in unpuddled regions, and eventually the puddle should reach the bottom, thus decreasing the concentration at that location. For this thickness decrease I have assumed the following expression.

$$
h_{p}=\frac{m^{\prime} T}{p_{i} \lambda}
$$

$$
\begin{aligned}
\text { where } h= & \text { thickness of ice melted }(\mathrm{cm}) \\
& \text { at the bottom of the puddle } \\
& \text { in time } T \\
m^{\prime}= & \text { amount of heat absorbed and used } 2 \\
& \text { to increase puddle depth (cal } / \mathrm{cm}^{2} \text { day) } \\
P_{i}= & \text { ice density }\left(\mathrm{gm} / \mathrm{cm}^{3}\right) \\
\lambda= & \text { heat of fusion }(\mathrm{cal} / \mathrm{gm}) \\
T= & \text { time during which reduction } \\
& \text { takes place (day) }
\end{aligned}
$$

The determination of the quantity $m$ ' is discussed in Section 3. Equations (1), (2), and (3) form the basis for the forecasting equations developed in the next section. 

3. Developement of computational equations

The quantities to be forecast are ice concentration and thickness changes due to melting effects alone. In all but areas of 10/10 coverage, equations (1) and (2) provide these results. The role played by equation (3) will be discussed later. Of the required inputs for these three equations, initial values of concentration, thickness, and puddling are available from the standard ice reports from reconnaissance flights,icebreakers, etc. What remains is to assign values to the density, heat of fusion, b, $m$, and $\mathrm{m}^{\prime}$. Each of these parameters will now be discussed and the final form of the equations will be derived.

Common to all models is ice density. Various investigators,principally Untersteiner, have shown that even during the melting season the ice density does not vary by more than $\pm 0.05 \mathrm{gm} / \mathrm{cm}^{3}$; so the commonly used value of $0.9 \mathrm{gm} / \mathrm{cm}^{3}$ is used throughout [3]. Also appearing in all equations is the heat of fusion. This quantity has been reported by Sverdrup, Johnson, and Fleming to vary over a wide range with changes in both temperature and salinity [4] (after Malmgren). Figure (I) shows the change with salinity for two temperatures. Since melting largely takes place at about $-I C$ to $-2 C$, curves (I) and (3), curve (2) of figure (1) is drawn for a mean temperature of $-1.5 \mathrm{C}$. Malmgren has also stated that sea-ice rarely exceeds a salinity of $7 \%$. From this discussion it can be seen that the heat of fusion can be approximated by equation (4). 



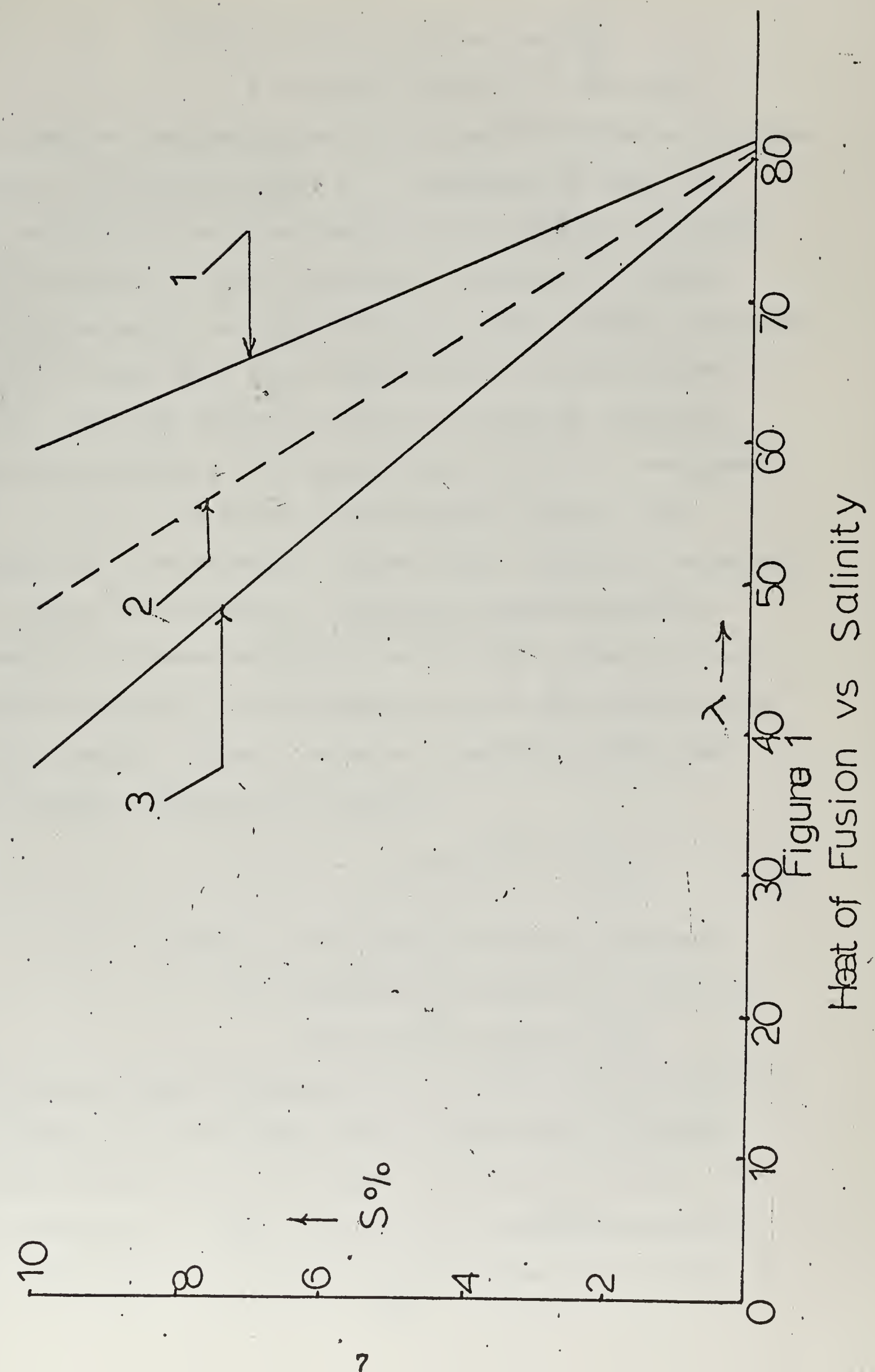





$$
\lambda=-3.3 S+80.5
$$

$$
\text { where } \begin{aligned}
\lambda & =\text { heat of fusion (cal } / \mathrm{gm}) \\
S & =\text { salinity (parts per thousand) }
\end{aligned}
$$

To complete the prediction of the heat of fusion at any time during the melting season it is necessary to know how the salinity of sea-ice changes as the season progresses. This quantity is rarely reported or measured in Baffin Bay. Experiments and observations to date are not conclusive on this point. As a first approximation it was decided to assume that the maximum salinity of $7 \%$ (aftbr Malmgren) was the salinity of the upper layer of the ice throughout the region at the start of the melting season. This. as sumption is more nearly correct when applied in equation (1) where the melting is a surface phenomenon, than in equation (2) where melting occurs on the sides of floes, where the initial salinity may be lower. For the duration of the season a linear decrease of salinity with time was assumed. Equation (5) results.

$$
S=-0.063 T^{\prime}+7 \%
$$

$$
\text { where } \begin{aligned}
S= & \text { salinity (parts per thousand) } \\
T^{\prime}= & \text { elapsed time since the start of } \\
& \text { the melting season (day) }
\end{aligned}
$$

To arrive at this expression the initial value of salinity was taken to be $7 \%$. Eight years of data from NAVOCEANO reports were used to determine a mean melting season for the region of 111 days with $a \sigma= \pm 10$ days[5]Substituting (5) into (4) yields equation (6), the final form of the 
equation for predicting the heat of fusion at any time during the melting season.

$$
\lambda=0.208 T^{\prime}+57.4
$$

The coefficient bT in equation (1) arises from the initial assumption that the quantity of heat absorbed by the ice is proportional to time. The actual relationship is very complex, depending upon changes in the physical structure of the ice,its albedo, puddling, wind speed, temperature, humidity, and other factors. For this model, however, $b$ is assumed constant and can be evaluated. In Baffin Bay the entire ice field is presumably zero at the end of the melting season;if one can specify the initial ice thickness and the length of the melting season, equation (1) can be applied. Using the eight years' data this evaluation was accomplished [5]. It was found that $\mathrm{b}=1.5 \mathrm{cal} / \mathrm{cm}^{2}$ day with $\sigma= \pm 0.1$. Zubov found $\mathrm{b}=1.6$ in the Kara Sea. The value found above was used in the initial forecasting attempts. To maintain program flexibility it is entered as a variable and may easily be changed should forecast results indicate the necessity.

The next parameter considered is the $m$ occuring in equation (2). This is the heat flux entering the water. There are a number of ways to arrive at a representative value of $\mathrm{m}$. Zubov considered $300 \mathrm{cal} / \mathrm{cm}^{2}$ day to be correct at $75 \mathrm{~N}$ latitude, This is a climatological figure with 
allowance for cloudiness and optical transparency of the water. This value was used initially. Laevastu has summarized several attempts to predict this figure and has a series of nomograms for forecast purposes; these were adopted in this study [6]. These nomograms have been programmed for digital computation but the programmed version was not used in this effort. Tabata also has a simple forecast scheme for use in non-advective areas which might be used $[7]$.

The final forms for computation are now found. Substitution of (6) into (1) gives

$$
h^{\prime}=\frac{b T^{2}}{2 p_{i}\left(.208 T^{\prime}+57,4\right)}
$$

Again using (6), enuation (2) becomes

$$
W_{t}=W_{0} e^{\frac{m T}{h P_{i}\left(.208 T^{\prime}+57.4\right)}}
$$

To summarize, other values which were used in the program were:

$$
\begin{aligned}
P_{i}= & 0.9 \mathrm{gm} / \mathrm{cm}^{3} \\
b= & 1.5 \mathrm{cal} / \mathrm{cm}^{2} \text { day } \\
m= & \text { forecast from weather parameters using } \\
& \text { Laevastu nomograms (cal } / \mathrm{cm}^{2} \text { day) }
\end{aligned}
$$

In equation (3) describing puddle growth, the same values of $\rho_{i}$ and $\lambda$ were used as in the preceeding discussion. The essential problems here are to determine when this expression applies and what value should be assigned 


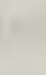

tre
(1)

(n)
$+$

+ 
the parameter 'm'. The equation is used to determine when puddling has reduced concentration to less than 10/10. It therefore applies only for areas of $10 / 10$ concentration in which puddling is reported. When puddle depth equals ice thickness, concentration is automatically reduced. Eauation (3) states that all puddles in an area will melt through at the same time. Thus, in areas of 10/10 concentration, the concentration should be reduced an amount equal to the puddled area. The original thickness of the ice is not uniform, however, and as a result this much reduction in concentration probably will not occur. For this reason the concentration is reduced to $9 / 10$. As the season progresses this figure should be adjusted to show greater reductions. The thickness of the floes is given by equation (7).

The evaluation of the quantity $m^{\prime}$ was done as follows. Examining several seasons' ice reports showed that within the first 40 days the puddle area growth was rapid, reaching generally 6/10 during this time. After 40 days the area growth slowed considerably and rarely exceeded 8/10 for the rest of the season. Therefore it was assumed that at the start of the season the amount of heat absorbed and used to increase puddle depth was 0.1 of that absorbed in the puddle, the remaining 0.9 being used for areal growth. Further, the heat used to increase puddle depth increased Iinearly with time until at 40 days 0.8 of the heat was used for this depth increase and the amount remained 


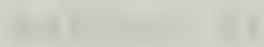

(n)

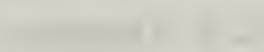

$+\frac{10}{20}$

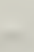

$\sqrt{10}$

.

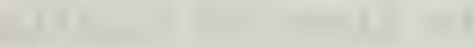

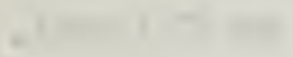

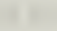

(1) 
constant for the balance of the season. It was further assumed that if the reported puddle area was $6 / 10$ prior to the 40 day time the figure $0.8 \mathrm{~m}$ would be used. These assumptions, expressed as ecuations (9), were then incorporated into the program.

$$
\begin{aligned}
& m^{\prime}=0.1 m+0.0175 T^{\prime}\left\{\begin{array}{l}
T^{\prime} \leq 40 \text { days } \\
\text { PuddLing }<6 / 10
\end{array}\right. \\
& m^{\prime}=0.8 m\left\{\begin{array}{l}
T^{\prime}>40 \text { days } \\
\text { Puddling } \geq 6 / 10
\end{array}\right.
\end{aligned}
$$

The quantities have the same definitions as before. Substitution of equation.(6) into (3) gives

$$
h_{p}=\frac{m^{\prime} T}{p_{i}\left(.208 T^{\prime}+57.4\right)}
$$

with $m$ ' being determined by equation (9). 

4. Programing technique

The approach to producing the final forecast was to first devise a program which would forecast concentration and thickness in 24-hour steps from consideration of melting effects. This is Program ICEMELT, Appendix A. It is the result of applying equations $(7),(8),(9)$, and $(10)$. The program is written in the FORTRAN 60 language for the 1604 computer. After this program was adjusted to produce fields that looked like nature to a degree, it was incorporated into Program ICEGRID to produce Program ICEGRID MODIFIED, Appendix B. The adjustments mentioned above established various continuity and error checks at program exits. The need for such adjustments became apparent when viewing initial outputs of the program. Following the establishment of ICEGRID MODIFIED, forecasts with real data were made using this program. Results are reported in a later section.

All programs use a 546 grid-point array of dimensions 26 by 21 to hold the data. All print outputs leave out the outer edge of this array. The distance between gridpoints is determined by the scale factor. A scale factor of one gives 60 nautical miles between grid points, two for 30 nautical miles, and so on. All forecasts made for this study used a scale factor of two. Scale factors larger than one, i.e.,grid sizes larger than 60 nautical miles, do not provide the detail it was felt desirable to have. 
Large grids also give rise to location errors. With a scale factor of two this error may be as large as 15 nautical miles. Another factor to consider at a larger grid size is the fact that the plane grid herein used will no longer be a good approximation of the spherical earth. There exist methods for handling this problem, but with the grid size used they were not required.

Data for the forecasts were obtained principally from the NAVOCEANO reports for the region [5]. Of course, in an operational situation the current weather prognoses and reconnaissance flight data would be used.

The forecast length is five days at 24-hour intervals. This conforms to standard practice in the operational forecast schedule. Smaller step sizes are not practicable with the current program because of the difficulty of forecasting the short-term flucuations of the weather parameters. The inherent errors and instabilities of the program are cumulative in nature. The five-day length of the forecast proved practical in effective isolation of these errors.

In program ICEGRID MODIFIED the outputs are concentration fields, direction fields, and distance of movement fields, forecast for five successive days following the input day. In addition the user may obtain the results of the incorporated ICEMELT by proper entry on the first data card. Land points are entered as the value 2.0 in the concentration field. Appropriate program instructions check these land points, and continuity between concentration 
and thickness, for proper entry into the computation ecuations. The program as it is presently written uses forecast values as input data for the next days' forecast.

In addition to these programs a very simple error analysis program was written to calculate the RMS-error of the concentration field, using equation (II).

$$
\begin{aligned}
\text { RMS - error }= & \sqrt{\frac{\sum f_{i} x_{L}^{2}}{N}} \\
\text { where } f_{i}= & \text { one } \\
x_{i}= & \text { difference between the observed } \\
& \text { and forecast concentrations at a } \\
& \text { grid point } \\
N= & \text { total number of the sample }
\end{aligned}
$$

Input data are the concentration fields,observed and fore. cast,for a specified day. The output is a print of the RMS-error. 

5. Results

First,computer runs were made using Program ICEMELT on observational data. Five-day forecasts which approximated nature were obtained. An m-value of $300 \mathrm{cal} / \mathrm{cm}^{2}$ day was used in these runs. No attempt,other than a subjective judgement and an arithmetic check, was made to verify these forecasts, since the wind drift would be the dominant feature. It was noted that the thicknesses were of the right order of magnitude, but that concentration changes appeared larger than one would normally. expect from melting influences. It was resolved that a more accurate attempt would be made to forecast the m-value for ensuing forecast periods. The climatological figure used by Zubov for an entire season appears unsatisfactory for the short-term forecast.

Following these first attempts, Program ICEGRID MODIFIED was used to forecast for the period 11-16 June, 1953. An m-value of $225 \mathrm{cal} / \mathrm{cm}$ day, derived from the Laevastu nomograms, was used. In this combined program of wind drift and melting effects the concentration results again showed excessive concentration reductions.

Upon re-examination of the assesment of $m$ it was discovered that a much wider variability of this figure than anticipated is ruite possible. Within the forecast area it may range from $20 \mathrm{cal} / \mathrm{cm}^{2}$ day to above $200 \mathrm{cal} / \mathrm{cm}^{2} \mathrm{day}$. To use just one value of $m$ appears arbitrary in view of this,but it was found that the use of a conservative figure gave reasonable results. 
With this in mind,examine figure (2), the forecast for 15 June,1953, which was made using a conservative mvalue of $35 \mathrm{cal} / \mathrm{cm}^{2}$ day. The lines in the figure delineate the edge of the ice field from the observed data, ICEGRID, and ICEGRID MODIFIED. An improvement over the Knodle forecast may be seen in some areas. The tendency of ICEGRID MODIFIED to over-forecast areas of initial high and low concentrations is especially evident in the area due North of Baffin Island. Observational data for the area along the north edge of the island show very low concentrations but not the open water forecast. It is true, however, that areas of increasing or decreasing concentration appear to be correctly located, although the magnitudes are in error. This is day four of the forecast. On day five results were unusable due to excessive drift and melt.

The next forecasting trial was for the period 12 to 17 May, 1959. The 17 May forecast is reported as figure (3). An important feature of this example is that the line delineating the edge of the ice has been subjectively smoothed. The basic guidelines for this smoothing were the original input data,previous days' forecasts, and the knowlege that ICEGRID MODIFIED tends to over-forecast areas of low and high concentrations. The decision to employ subjective smoothing was greatly aided by the results of the RMS error analysis, reported in section 6. As can be seen from figure (3) this smoothing improved the forecast materially. 
Since it seemed likely that the smoothing might be influenced by having avallable the Knodle forecast and the observed edge of the ice, a run of ICEGRID MODIFIED was made for the period 4 through 8 June,1957. The 8 June forecast is shown as figure (4). The smoothed line locating the edge of the ice field was drawn following the precepts mentioned without prior knowlege of the observed edge. Again results are in accord with the observed edge.

These three periods were the only ones in which forecasts were made due to time limitations. They represent a total of 15 forecast days from three different years and appear to yield useful information. Some of the difficulties encountered would not be present in field forecasting. The forecaster would have an up-to-date synoptic picture coupled with a more extensive background. There would not be the delays in receiving results that were present here due to the extensive student use of the computer. Further sections discuss errors, recommendations, and conclusions on the basis of these results. 


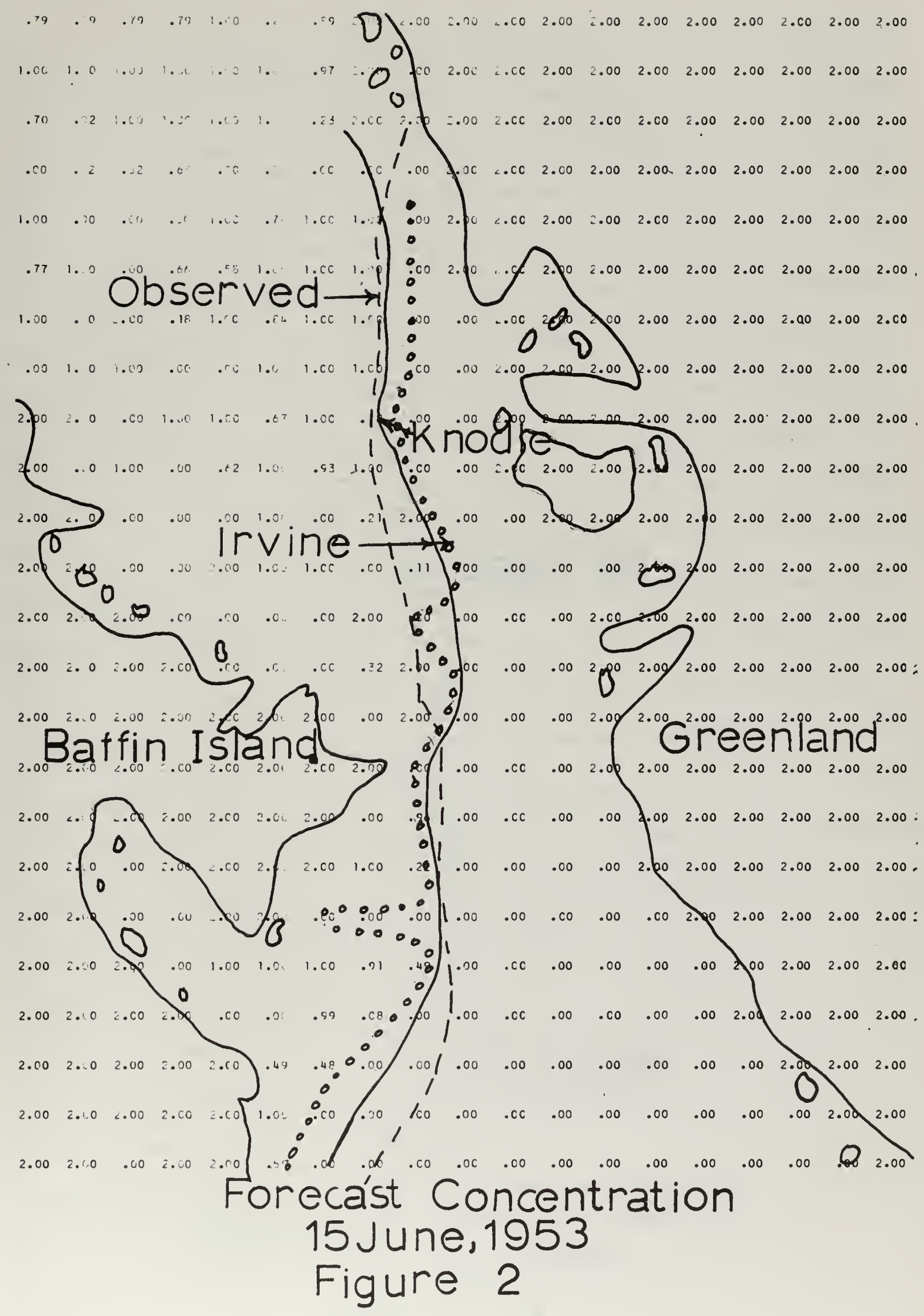





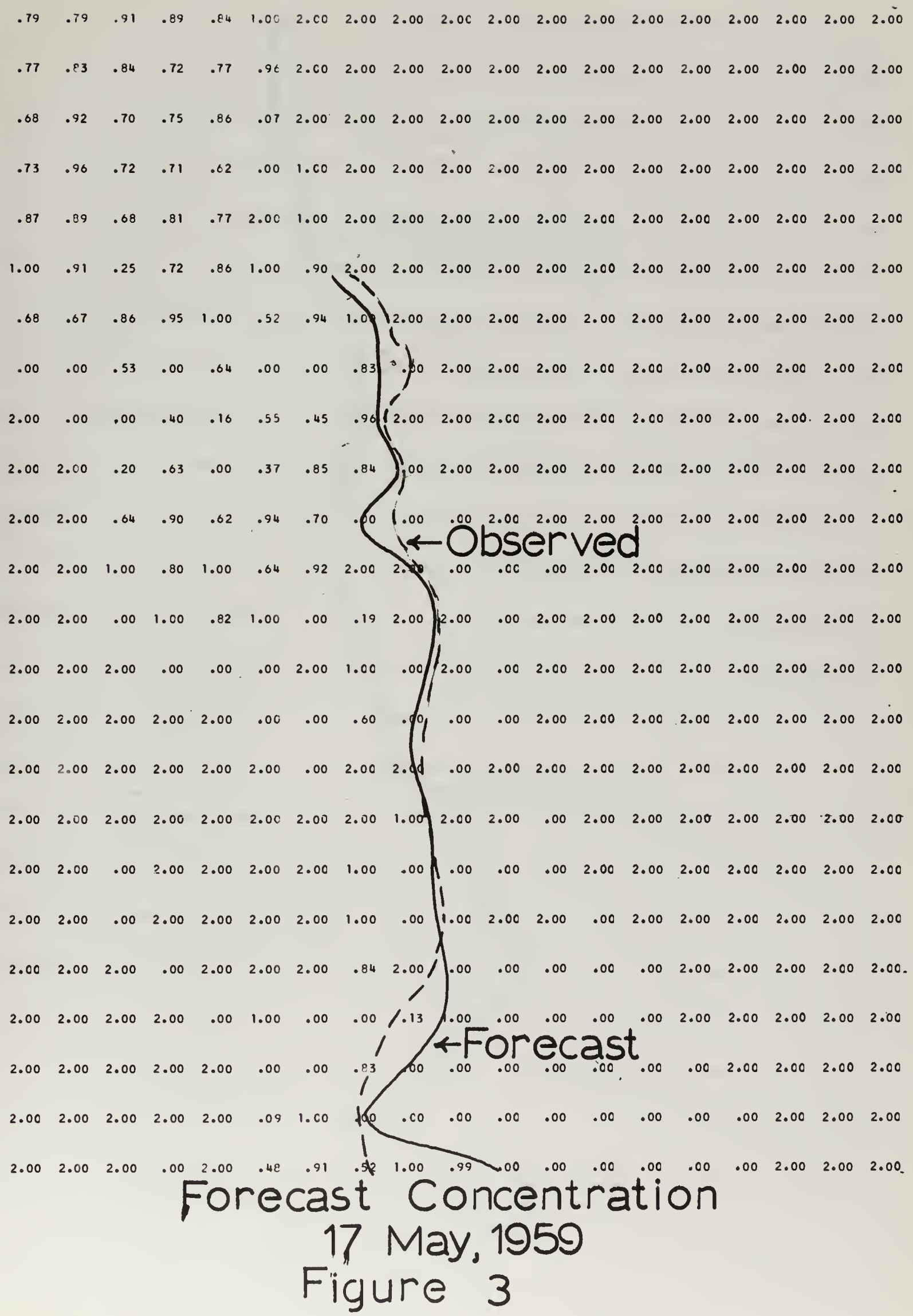





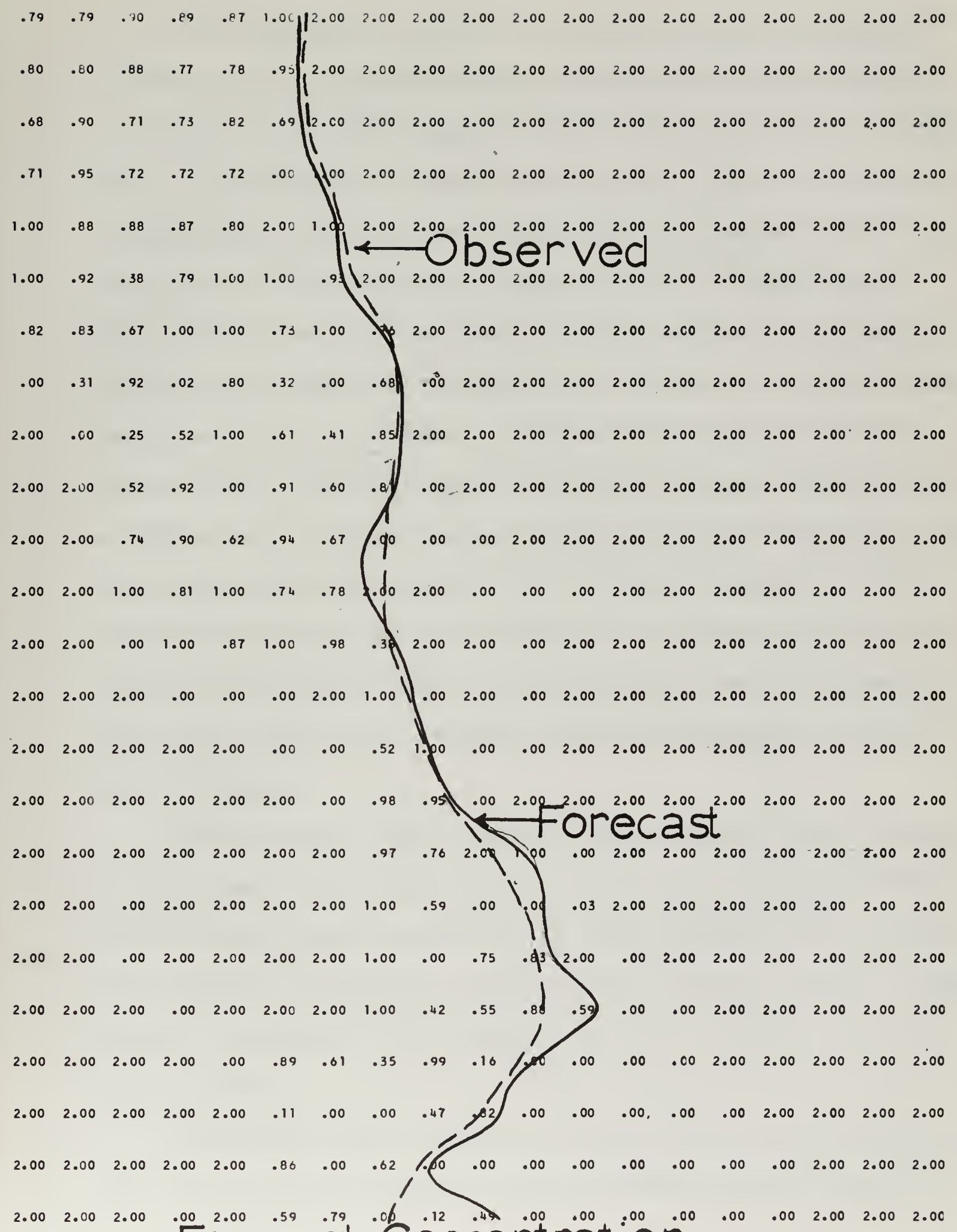

Forecast Concentration

8 June, 1957

Figure 4 

6. Limitations and error analysis

Objective error analysis

The program described in Section 4, which produced a RMS-error of concentration,was applied to the results of ICEGRID MODIFIED, using observed data for the comparison. For 15 June, 1953 the error was 0.24. This error was in excess of the observational error,estimated to be 0.1 . If it can be shown that a large portion of this error was contributed by the areas of high and/or low concentration more accurate subjective judgements of the forecast could be made. Therefore, a run was made omitting those areas with a forecast value of $0 / 10$ concentration,giving a RMS-error of 0.14 . The next step was to eliminate, in addition,grid locations which had a forecast value of $10 / 10$. The RMS-error now became 0.06, which is less than the observational error. Thus, by eliminating from the forecast both zero and total coverage areas an accurate forecast was obtained.

For the same date the RMS error of the Knodle program, ICEGRID, was 0.1 . Thus, it can be seen that program ICEGRID MODIFIED has the possibility of being superior to ICEGRID if a method of dealing with the areas which forecast excessively is devised. The program is more accurate except in these areas.

It appears that computer instability is at fault, even with only five-day steps. A more sophisticated method of 

step-wise approximation, such as the Runge-Kutta model, time averages using past days' results, space averaging about surrounding grid points in the melt forecast portion of the program, or some similar treatment might smooth out or decrease this instability. However, none of these methods were applied in this thesis:

The thickness forecast of ICEMELT was spot-checked by hand calculation.' Starting with the input thickness the hand calculation was perforned for the five days and compared with the observed thickness at the grid location at the end of the forecast period. In all cases, the forecast value was within the observational error. This portion of the forecast denends on $b$. If the melting season is radically different from the climatological mean, or the oricinal ice thickness is anomalous, a climatological $b$ will no longer be proper. However, the program permits the forecaster to change $b$ if this appears to be necessary.

Heat budget

In the heat budget expressions two coefficients must be determined empirically, $b$, which is related to heat absorption by the ice, and $m$, the heat absorbed by the water. Recall that b was calculated on the basis of total disappearance of the ice at the end of the season. Since much of the melt takes place in puddled areas, other melting stems from heat in the surrounding waters, and considerable 

ice is removed advectively, this $b$ is probably too large. Melting seasons may vary considerably. For example, Melville Bight, during 1965, had anomalous temoeratures and 10/10 ice, a highly unusual situation. It is unrealistic to assume that the b-value of previous years would apply in this situation.

Perhaps $\mathrm{b}$ can be evaluated at data points where advection is small; then adjustments can be made during the season from icebreaker reports and reconnaissance flights. By hand this would be tedious, but using a computer it becomes feasible. For five-day intervals ICEGRID MODIFIED is not sensitive to thickness changes, which depend upon b. However, on of the aims of the program is to provide information about little observed areas, so the influence of $b$ on $h$ ' must be considered over longer periods. In this time frame, thickness changes do have a significant effect and the b-value assumes new importance.

As was discussed in section 5, a very conservative figure for $m$ had to be used to produce usable forecasts. This value was an order of magnitude smaller than the climatological figure for the area. Too few cases were tried to establish whether this should be true in general, but it does cast a shadow on the ability of the equations and assumptions to provide a short-term forecast. To determine more exactly the validity of these items an m-value for each grid location could be forecast. Other heat distributing processes, particularly advection, could be considered 
to modify the m-values used here. Further, the m-value determines what is to be used for $\mathrm{m}^{\prime}$ in the puddling expressions, so error in $\mathrm{m}$ can be re-introduced into the program. The determination of $\mathrm{m}^{\prime}$ is considered to be a first approximation only. More investigation of the heat budget in puddles is necessary.

Permanent currents

The program does not consider the effects of currents. Observed advection of ice by currents often has the same magnitude as the Wind drift component; so this forms a major possible source of error. Currents could be incorporated into the prediction and would probably improve results.

Hummocking and ridging

The roughness coefficients are assumed to be constant during the drift period and over the entire space field. Changes in hummocking and ridging would affect calculations of wind drift by changing the roughness parameters; they also change the melting process. For melting, a flat, uniform field is assumed, however, the slopes of the hummocks and ridges absorb heat differently than a flat surface, thus changing melting rates, the formation of puddles, and the observed thickness. However, the size of these roughness features is not reported, only their presence; so it is only by some qualitative means that they could be nresently accounted for. In addition to their indirect influences, hummocking and ridging 
affect both surface and subsurface navigation, and travel over the ice; more detailed and quantitative reports on their characteristics are, therefore, doubly desirable.

Transport from outside the area

No consideration is given either to ice transport or to horizontal heat advection across the boundaries. These omissions may lead to erroneous forecasts near the boundaries. There are several means of dealing with this. A partial solution used in the existing program is to omit one row and one column of data at the edge in the final printed result. Another method for treating boundary effects is to change the data at the boundaries as common sense and climatology suggest, ignoring forecast values there.

Near shore ice drift

Near shore ice drift has a quite different character than drift offshore. To adequately described it would require entry into the machine with not only boundary location but orientation at each point. At present ICEGRID MODIFIED considers ice concentrations at adjacent land points as $0 / 10$ and 10/10 for off shore and onshere winds, respectively, for computing concentration changes near shore (after Knodle).

Transient states in the ice field

Transient states may be introduced in the ice forecast by short-term flucuations of the wind field or insolation. If these flucuations are of a duration less 

than a day the program will not detect them. In addition transients may be induced from the change from one steady state regime to another, due to inertia, even though diurnal variations are not considered. The program has no means of dealing with these, only the steady state condition is recognized.

Observational data

At the present time the principal source of data is U.S. Navy reconnaissance flights from Argentia, Newfoundland, supplemented by icebreaker reports. The flights are generally twice weekly, and cover only that portion of the area most critical for resupply operations to Greenland bases. Thus, the location of the edge of the pack is well defined, leads close to Greenland are known, but little is observed of the rest of the area. Observation is largely subjective and may contain considerable error. As presently reported, data are not readily adaptable to digital methods. The reports must be plotted on charts before being transferred to punch cards. This is time consuming and some other means must be found before a digital forecast can compete with hand forecasts on a time basis.

Further, weather data for the region are sparse. This means that an accurate heat budget forecast: and wind field prognosis are extremely difficult. 


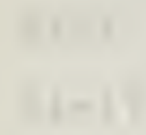


Programming language

The language used was FORTRAN 60, which is easy for the tyro programmer to understand but has several disadvantages. Wind forecasts are not available in this language; so the wind forecast must be derived from prognostic charts, then entered on punch cards. Again a loss of time results. In all, it takes 15 hours to ready a data deck for the forecast. In an operational situation this time could be halved but it is still long compared to the five minutes it takes the computer to make the forecast. 

7. Recommendations

Several considerations are invited by a review of the preceeding sections. There is a need for more data and for better means of observation. Remotely controlled nuclear powered stations may in the future provide some answer. Satellite observations could prove helpful, although at present the small scale features of interest are not detected by the TIROS system.

The program should be written in language compatible with existing weather programs, so that direct input from reporting stations to computer is possible.

The existing program should be modified to include at least permanent currents. A smoothing function should be employed to control stability. With these modifications a large number of forecasts should be made and verified, and a statistical error analysis should be nerformed. An attempt should be made to obtain better $m$ and $b$-values, perhaps including laboratory studies of melting of ice. Changes of the heat of fusion with time should be more fully investigated.

Another approach to the melting effects could be made using the degree-warming-day concept and results compared with ICEMELT. 



\section{Conclusions}

In the foregoing sections the developement of a modified wind drift program to include melting effects has been shown. It is concluded that melting effects are pertinent to improvement of forecast accuracy. However, it is also noted that further work is required to produce smoother and more stable forecasts using this program. Although data preparation detracts from the speed of this objective method, it is felt that it is superior to hand forecasts by subjective means because of its potential accuracy and detail, and because identical results will be obtained no matter who does the work, provided the input data are the same.

Further, there does exist a great need for improved data gathering networks in the Arctic region. For all the recognition paid this area by the world, adequate physical description is lacking. 



\section{Bibliography}

1. Knodle, W.C. A computer program for forecasting the wind drift of sea 1ce. Thesis, U.S. Naval Postgraduate School, Monterey, Cal1f. 1964

2. Zubov, NoN. Arctic 1ce. Hydrometeo Press, Moscow, 1943. ( Translated by U.S. Naval Oceanographic Office, American Meteorological Society, and the U.S. Naval Electronics Laboratory.)

3. Untersteiner, $\mathrm{N}$. Calculations of temperature regime and heat budget of sea ice in the central arctic, Journal of American Geophysical Research, Vol. 69, No. 22 Nóv. 1964

4. Sverdrup, H.U., Johnson, M.W. and B.H, Fleming The oceans, their physics, chemistry and general biology. Prentice-Hall, Inc, 1942

5. Wittman, WoI. Report of the arctic ice observing and forecasting program. 1953 through 1961 SPa70(60)

6. Laevastu, T. Factors affecting the temperature of the surface layer of the sea. Helsinki, 1960 (. Communicated May 16, 1960 by I. Hela and L。A. Vuorela)

7. Tabata, S. The effect or heat exchange and winds on the summer temperature structure of the surface water at station "P" in the eastern subarctic Pac1fic Ocean. Fisheries Research Board of Canada, Pacific Oceanographic Group, Nana1mo,B.C. 15 Fob., 1962 



\section{PROGRAM ICEMELT}

\section{Description}

This program computes sea-ice concentration and thickness using equations after Zubov. Thickness and concentration fields are for 21 by 26 . Inputs are ice concentration, thickness, puddling, coefficient of heat absorption, density, elapsed time of melting season, and scale. The purpose of the program is to produce five-day forecasts of thickness and concentration due to melting effects alone.

Table A-l defines the variables in the program language. The complete program is listed following this discussion. Data Input

Data input is accomplished by IBM cards with the values punched on them in decimal form. Constants are also entered in this fashion.

The first data card specifies the scale, the base latitude, ice density, the constant $b$, the m-value, and the -lapsed time since the melting season began. Neither scale nor base latitude are used in the program although they could be printed out as a handy index. The base latitude establishes the northern-most boundary of the grid and is always the latitude of the boundary plus the inverse of the scale factor (after Knodle). The next 14 cards specify the concentration field. Land points are entered as 2.0 

Following these are 14 cards for the thickness. Land points may be entered as 0.0 or 9.0 . The last 14 cards are the puddling field entered in tenths.

Output of results

Five forecasts of concentration and five of thickness are printed; one of each on each day. On all printed grids the outer boundary points used in computation are omitted. Preceding all the forecast results is a print of the input concentration. 

TABLE A-I

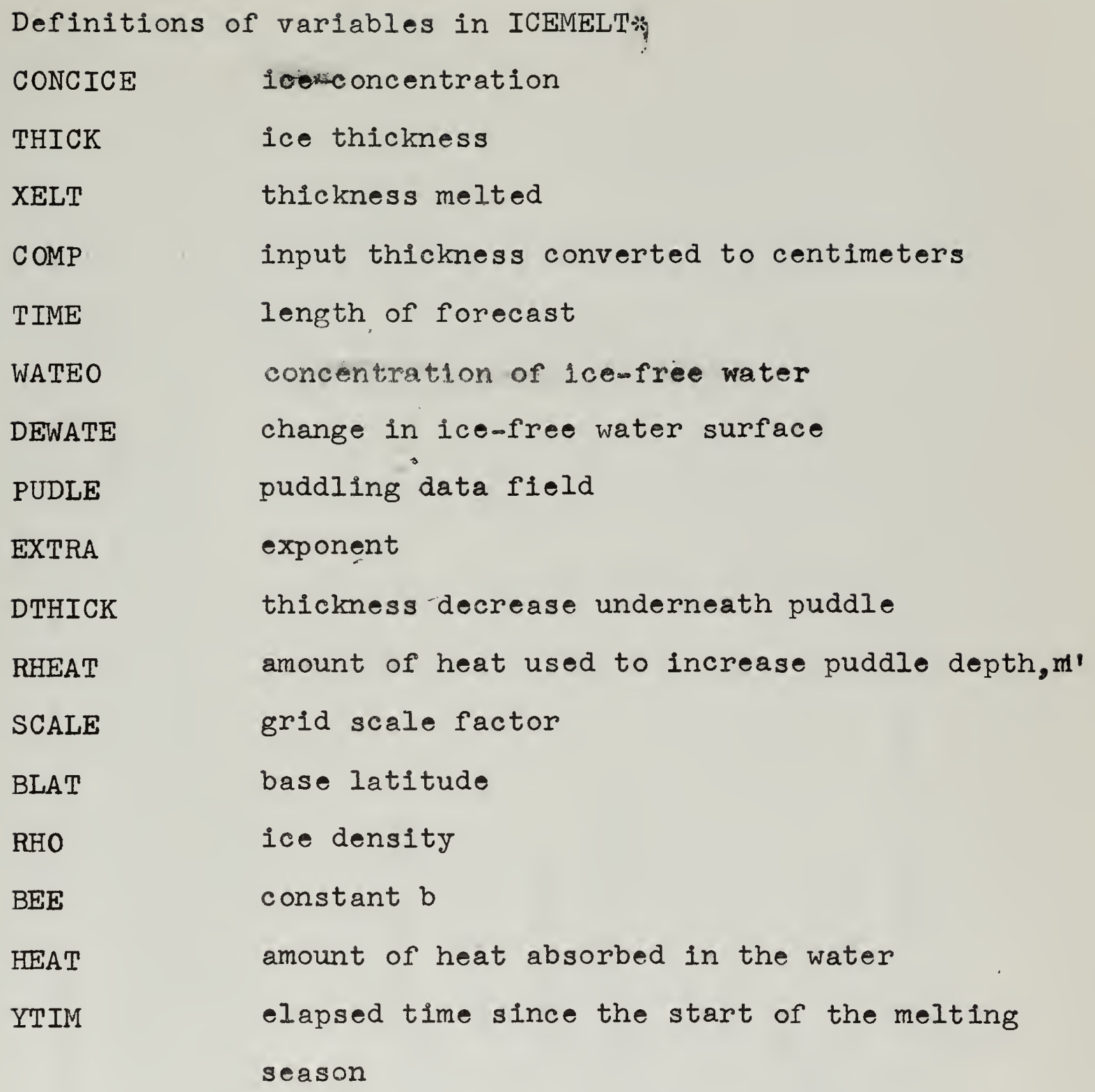

* Note: Some variables in the DIMENSION statement of ICE. MELT are not used in the program and are therefore not defined. See Appendix 



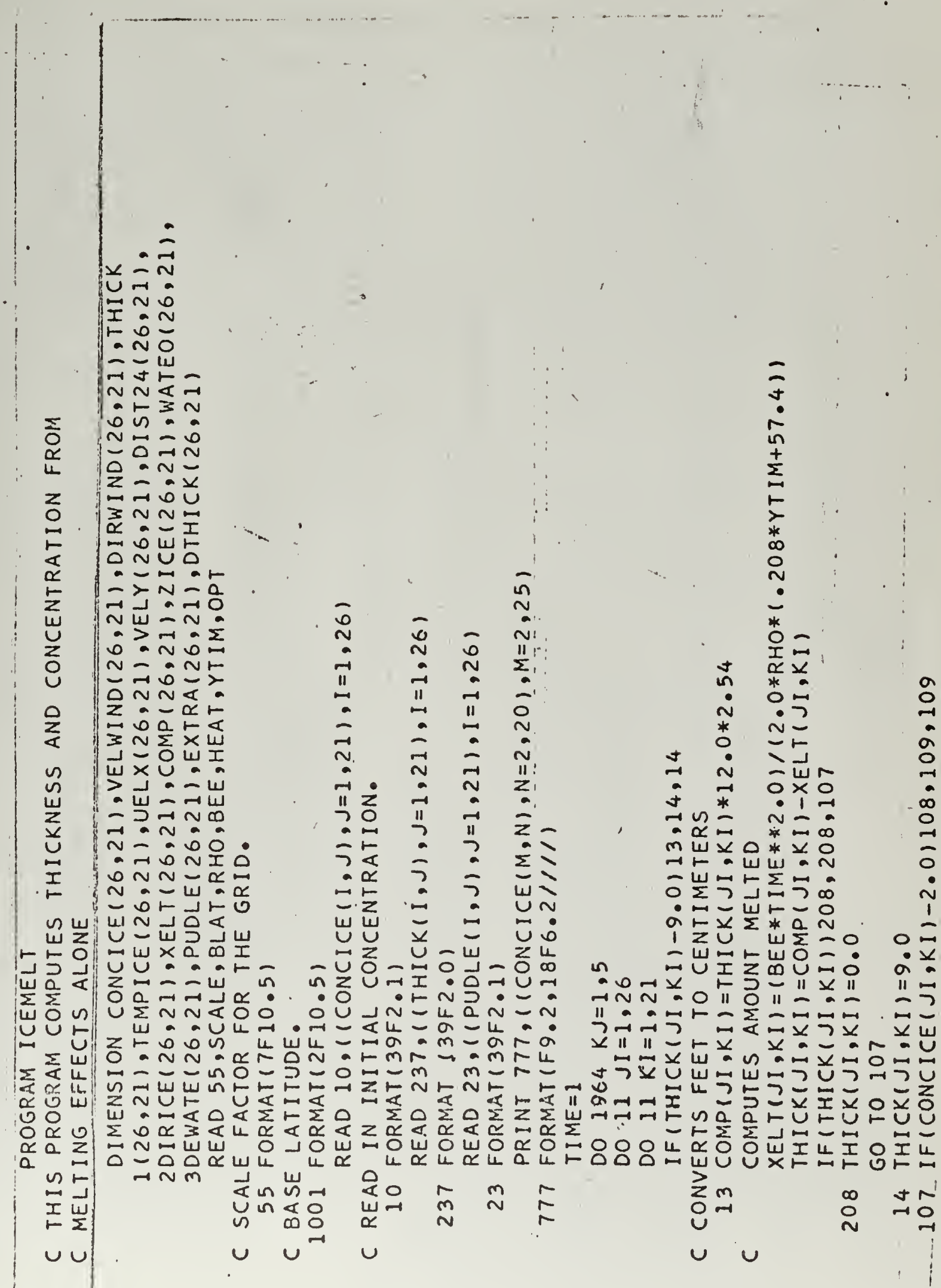





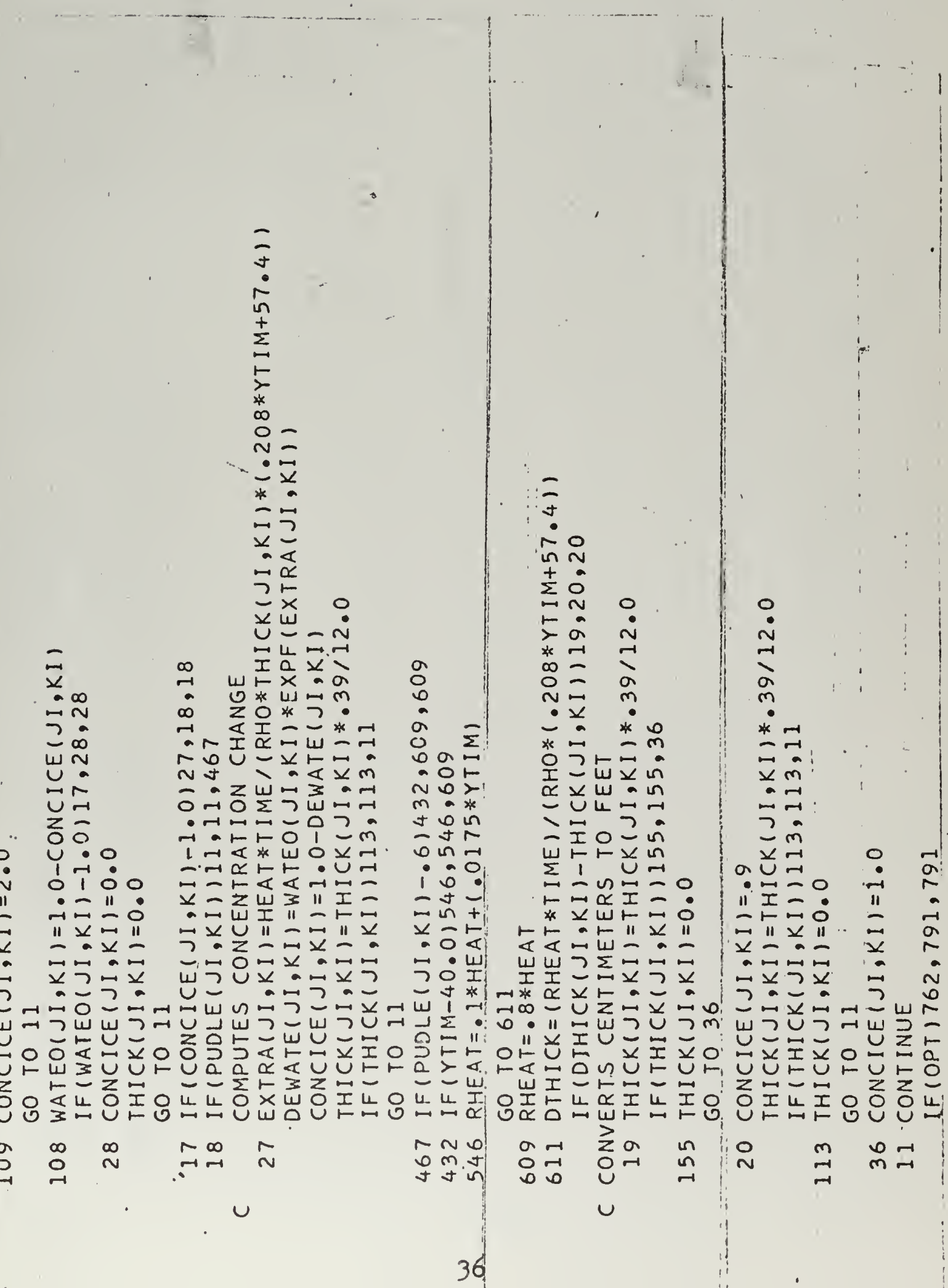





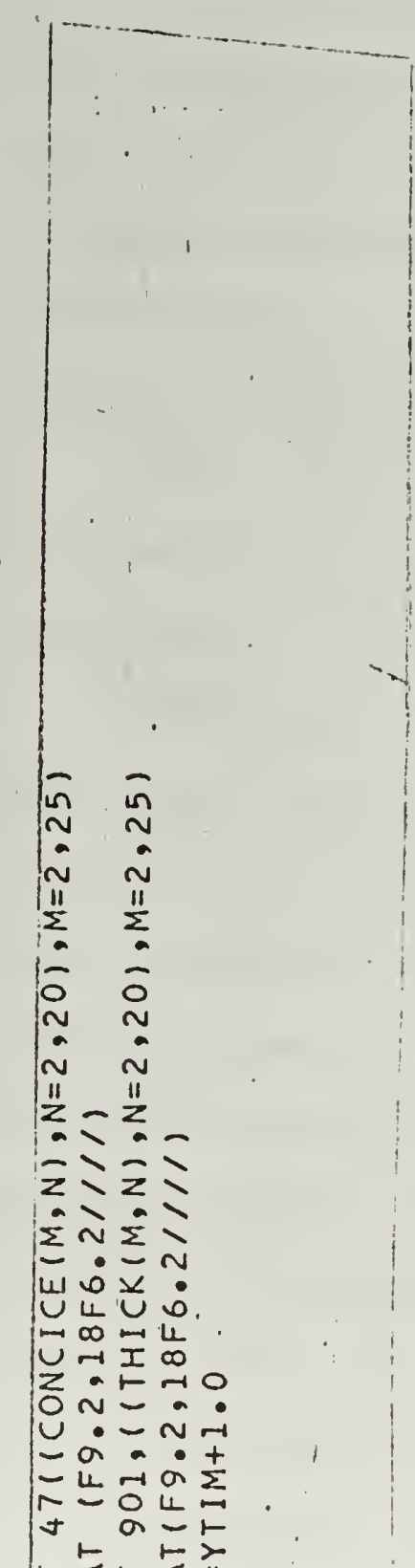

些上正坚

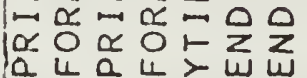

(

No $0 \vec{a}$ 



\section{APPENDIX B \\ PROGRAM ICEGRID MODIFIED}

Description

This program computes wind drift of sea-ice with a modification for melting. . Computations are for a 546 point array utilizing latitude, ice thickness, concentration, wind speed, and wind direction as inputs. The purpose is to produce five-day forecasts of concentration, direction and distance of movement. The user has the option of receiving a print of the melt effect concentration and thickness forecasts by proper entry on the first data card.

Table Bl defines the variables used in the program. The comnlete program is listed following this discussion. Data input

Data input is accomplished by using values punched on IBM cards. The first data card contains the scale factor, the base latitude, which is always the northernmost boundary of the grid, plus the inverse of the scale factor. This card next has the ice density, the constant $b$, the value of $\mathrm{m}$, and the elapsed time since the start of the melting season. The last field on the card is used to indicate if a print of the melt forecast is desired. If the field is left blank, the print will not occur; if it is entered with any negative number, the melt forecast results will be printed. The next card contains the values of the friction coefficients. Following are 14 cards specifying the concentration field, then 14 cards for the thickness 

field, 14 for the puddle field, 14 cards for wind speed, then 21 cards for wind direction. Following are groups of 14 and 21 cards for the wind speed and direction for each of the forecast days. Ouput of results:

Results are printed in grid form with the outer boundary points omitted. The input concentration is reproduced as the first output. This is followed by grids of concentration, direction of movement, and distance for each of the five days. If the user has selected the optional melting forecast output, a melting concentration field and thicknoss fiold will precede the above on each day. 



\section{TABLE B-I}

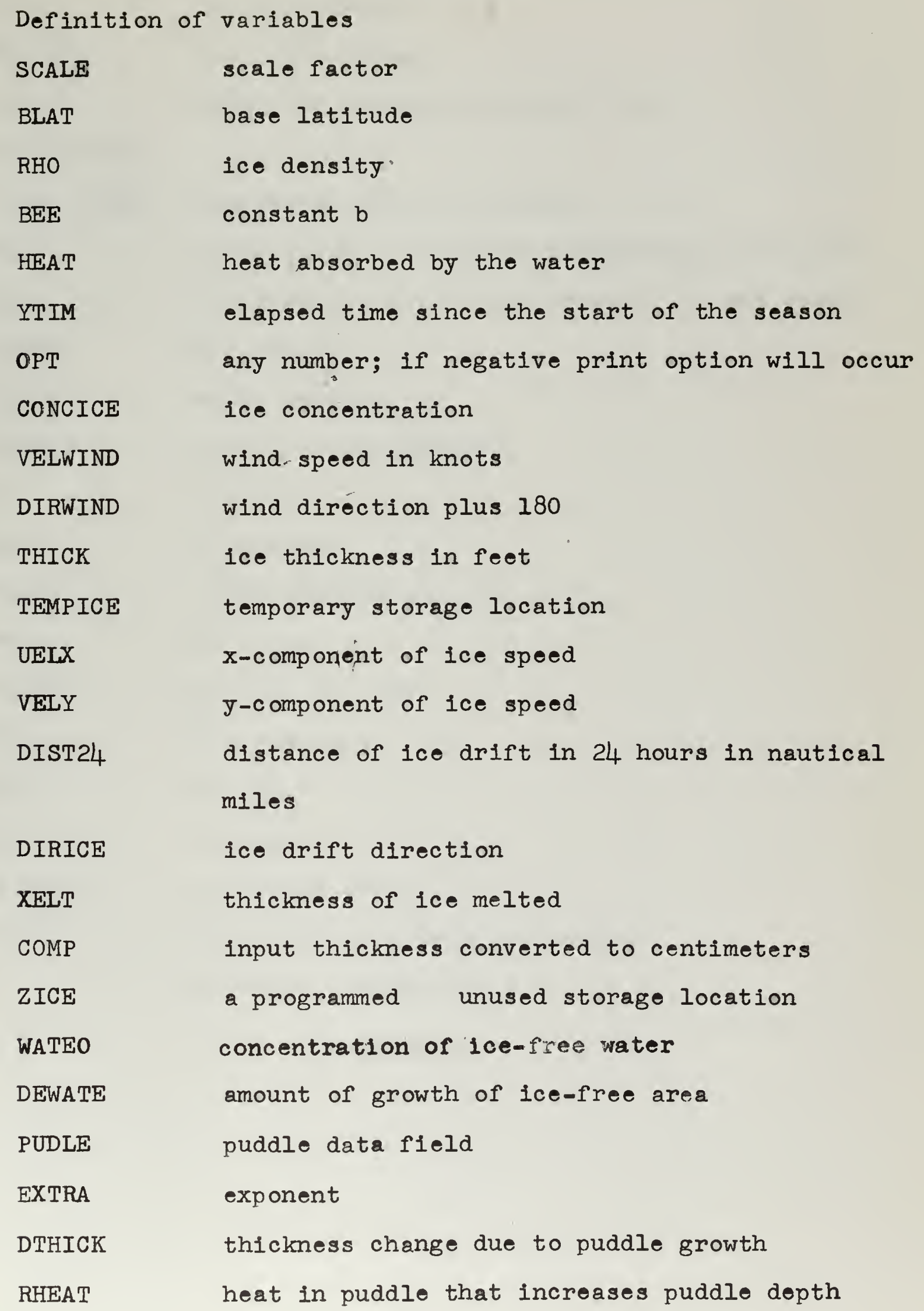



TIME

PLAT

VELICE

DCDT

YICE, YYICE

SICE, XXICE

AKA

AKW

RHOAIR

DSUBW

OMEGAB

$\mathrm{XI}$

ENN

ALFA

BETA

SQMASS

BBB

PSIO

PSI

CONFAC

VVICE

C in days, from the start of the forecast

latitude, degrees

ice drift speed

change in concentration with time

temporary storage locations

coefficient of friction between air and water

coefficient of friction between ice and water

air density

water density

coriolus acceleration

variable

a constant

drift deviation angle

90 - alfa

mass of the ice

$\mathrm{B}$, a constant

an angle

an angle

modifying factor

ice drift in meters per second

constant, normaliy one 



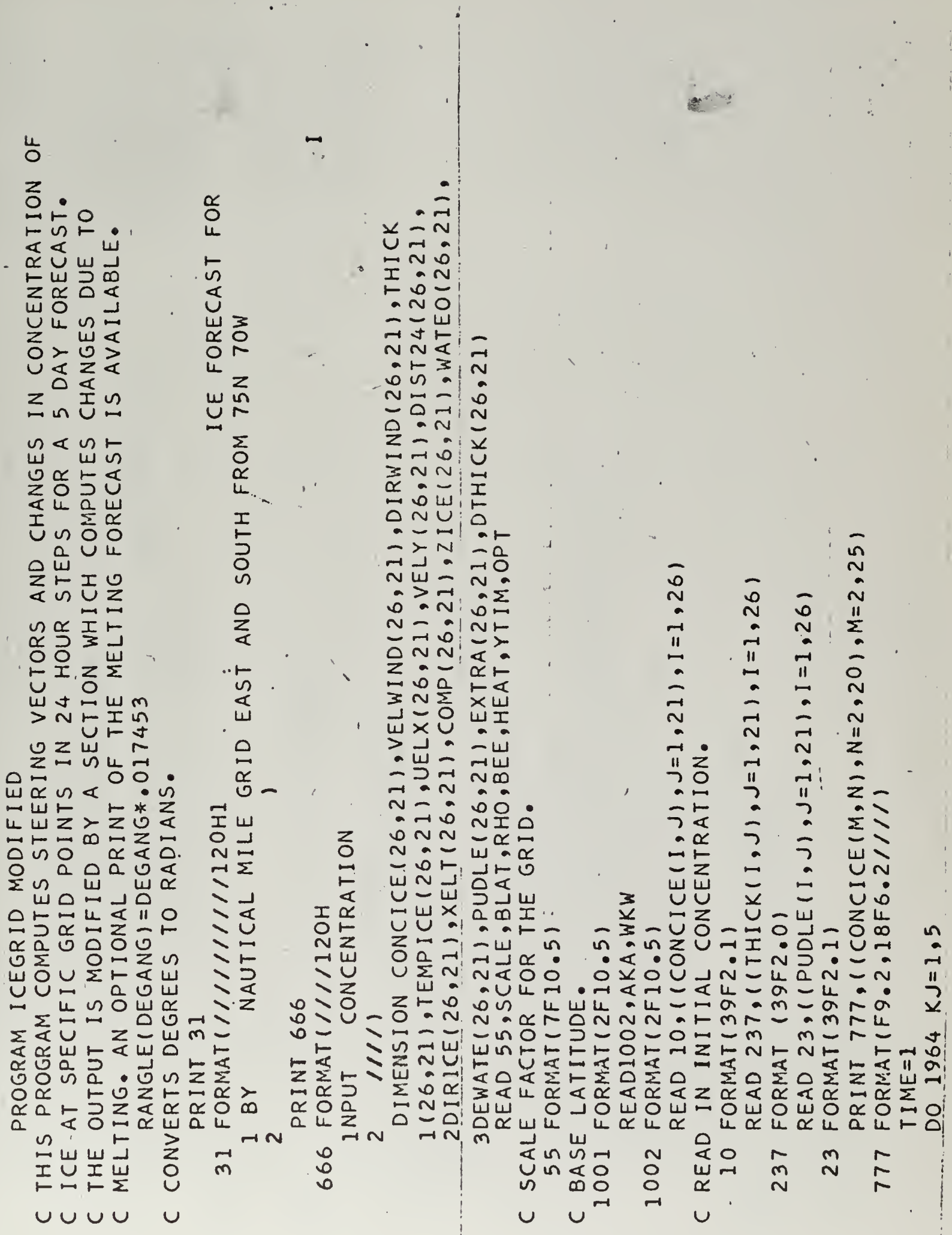





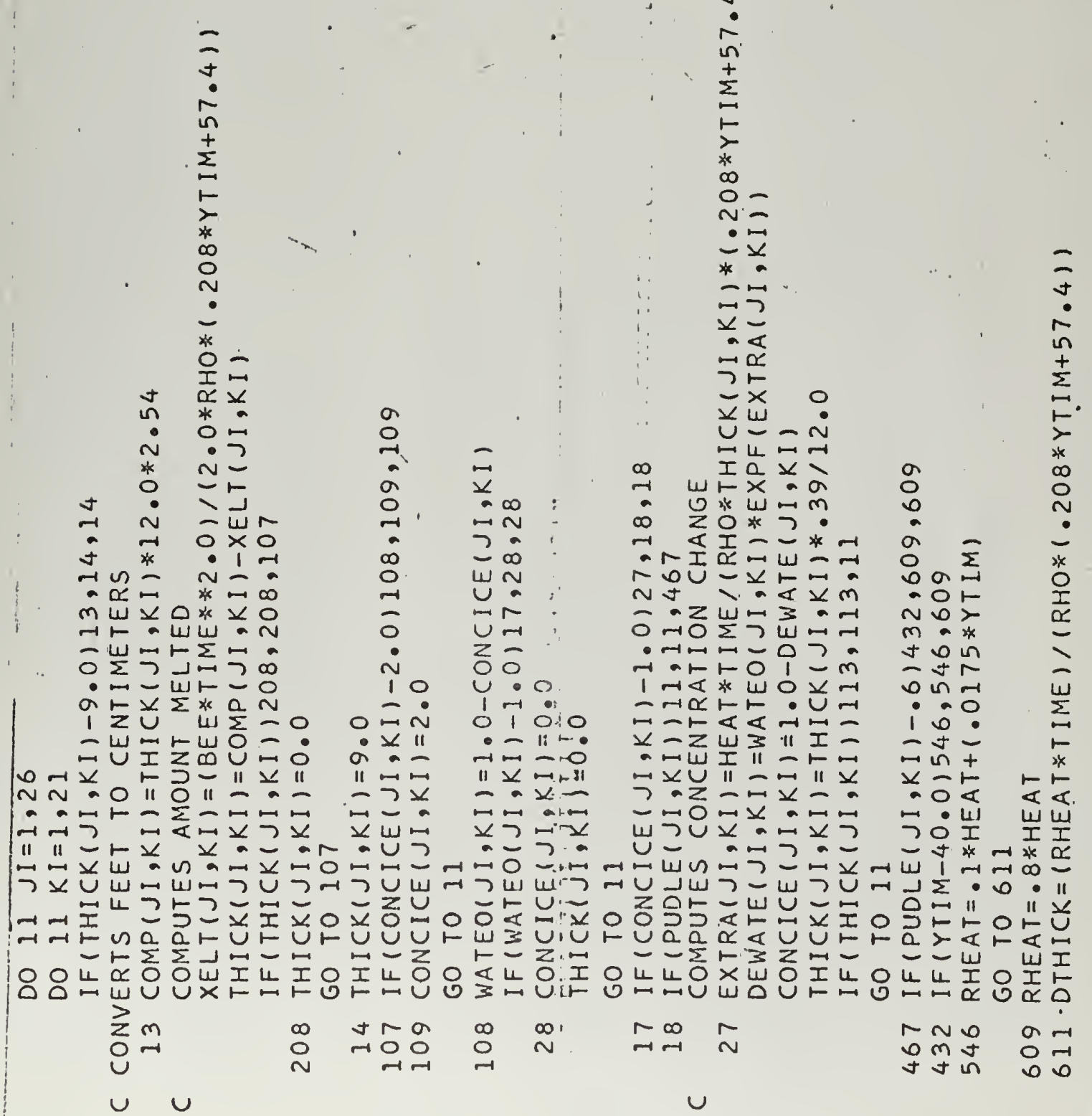




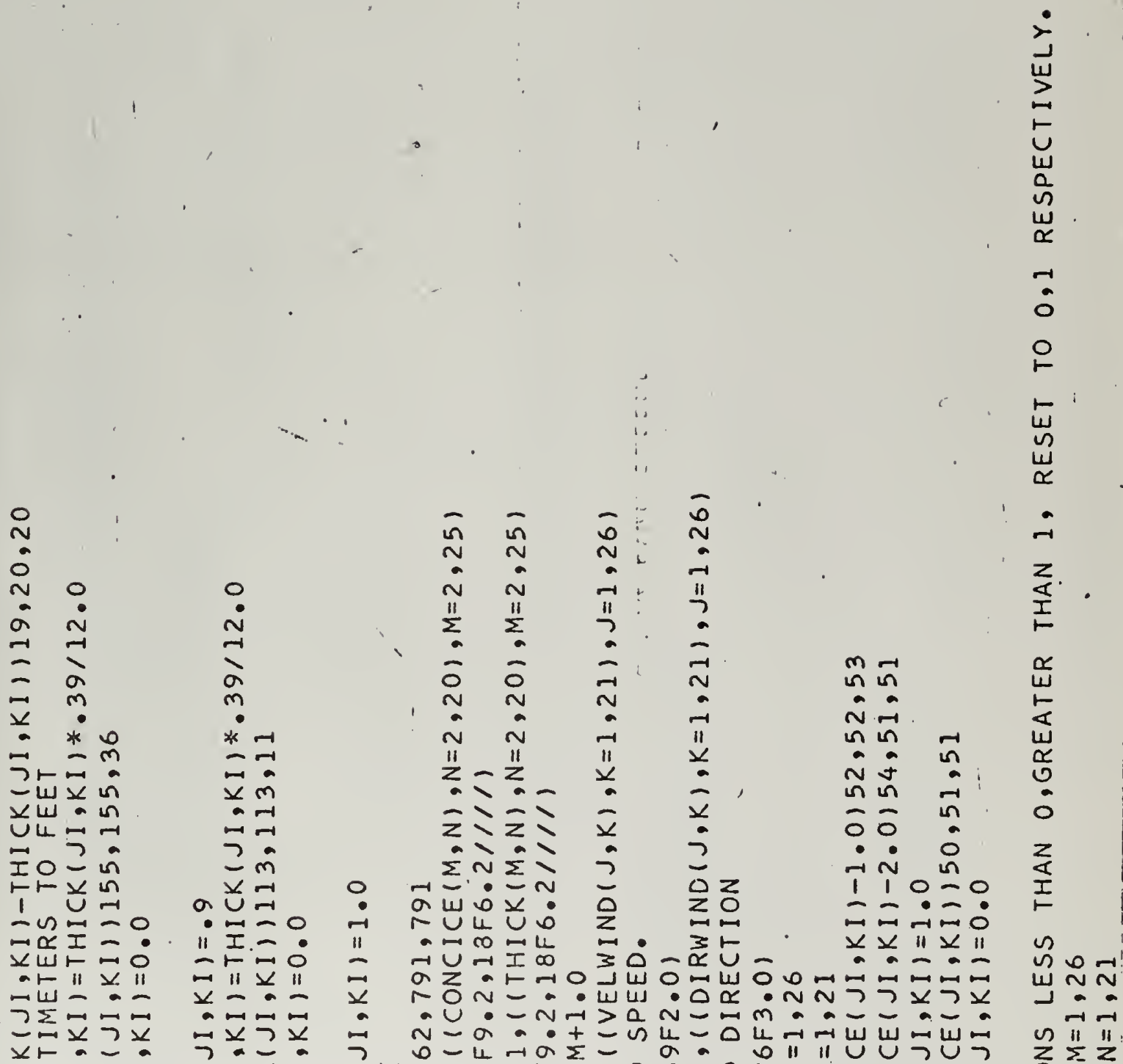

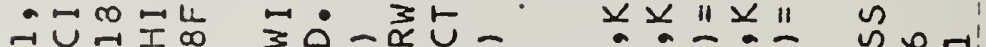
वz

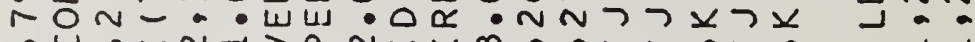
$\therefore U \cdot-N-N>a-m m a-a-a-a$

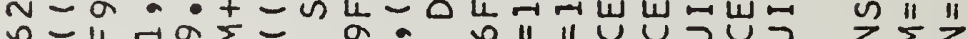

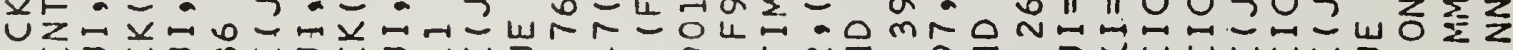

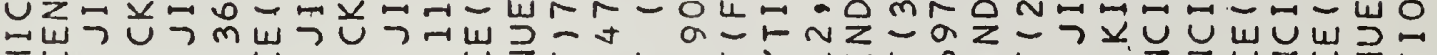
IU

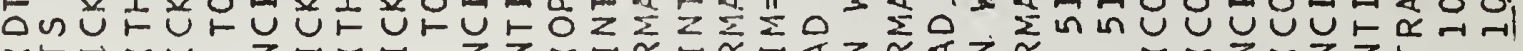

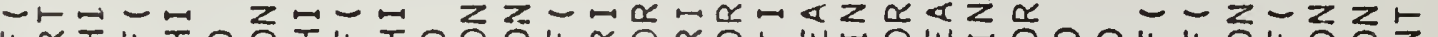

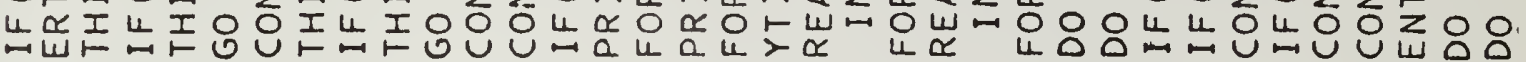
Za n 0 m 0 n N

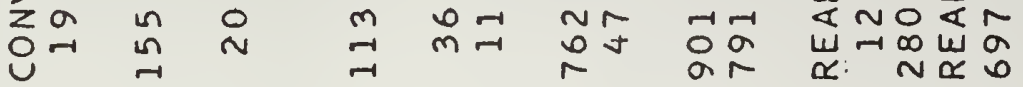
u $\cup \quad \cup$ $m+N 0 \rightarrow \geq$ in $\ln$ in in in 



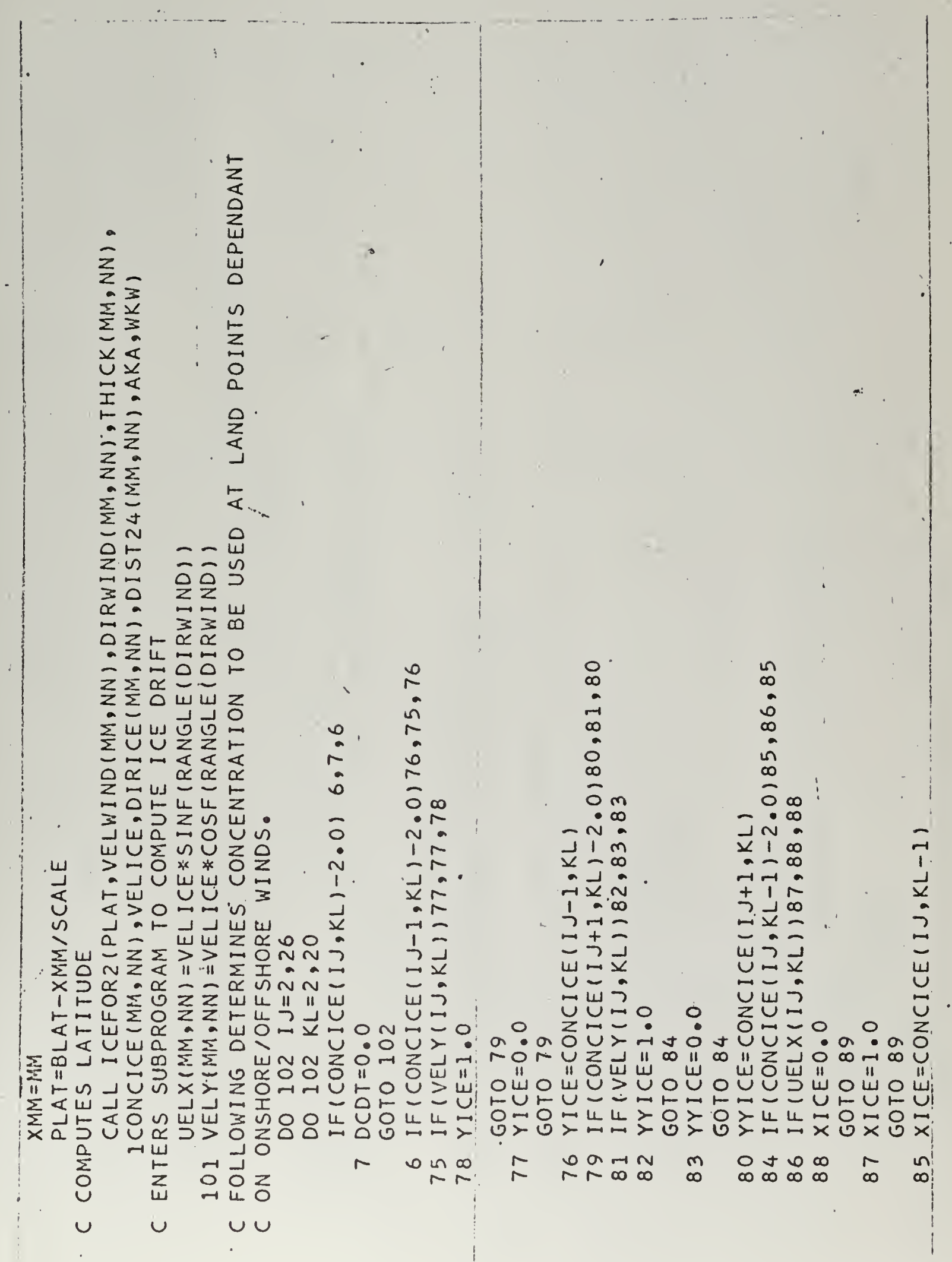






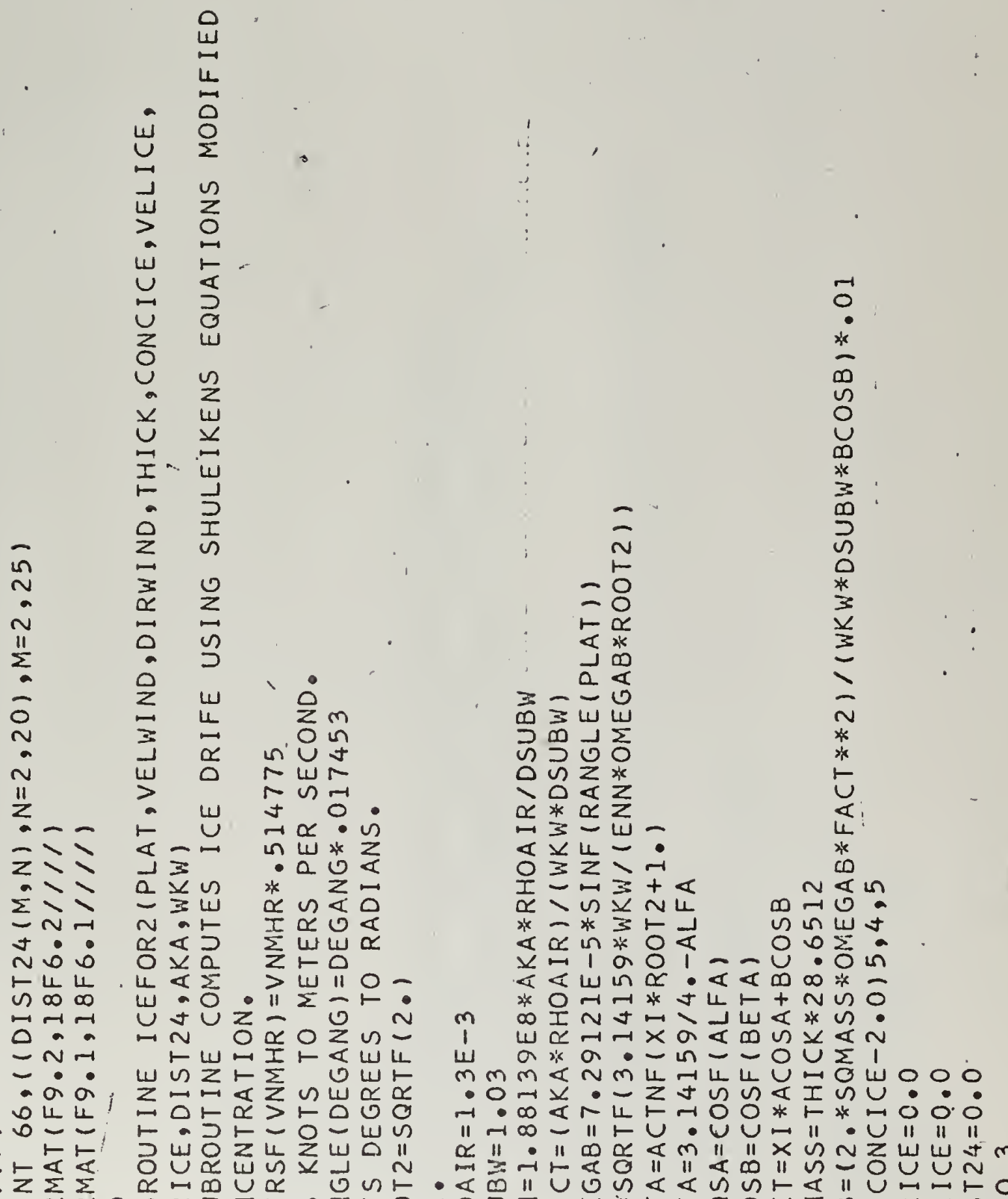

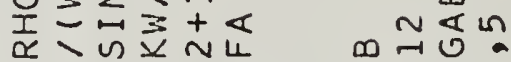
*

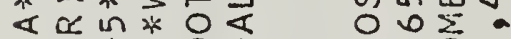

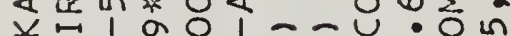

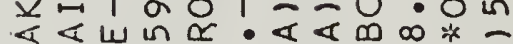
* 0 न

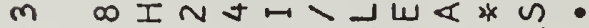

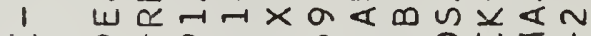
us a a - n $m m m \ll n m \amalg$ - ONV. - Z

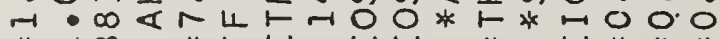
$\|\sqcap \infty-\| \vdash \cup \bullet \cup \cup \mapsto\|\bullet\|$

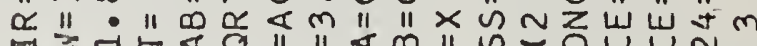

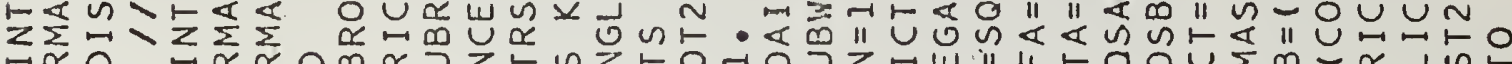
$+-<-0-1-2-0-4 u$

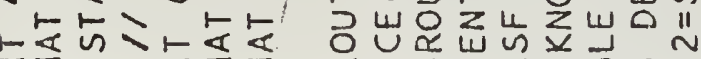

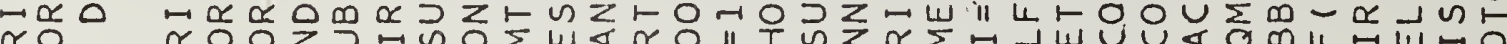

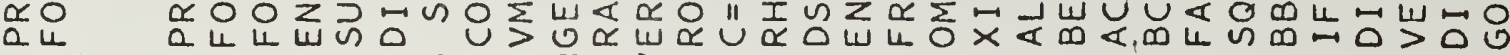

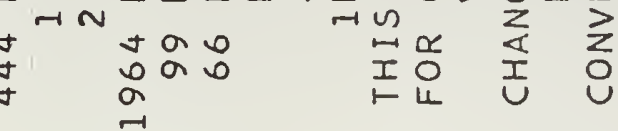

$$
\begin{aligned}
& \cup \cup \cup \cup
\end{aligned}
$$





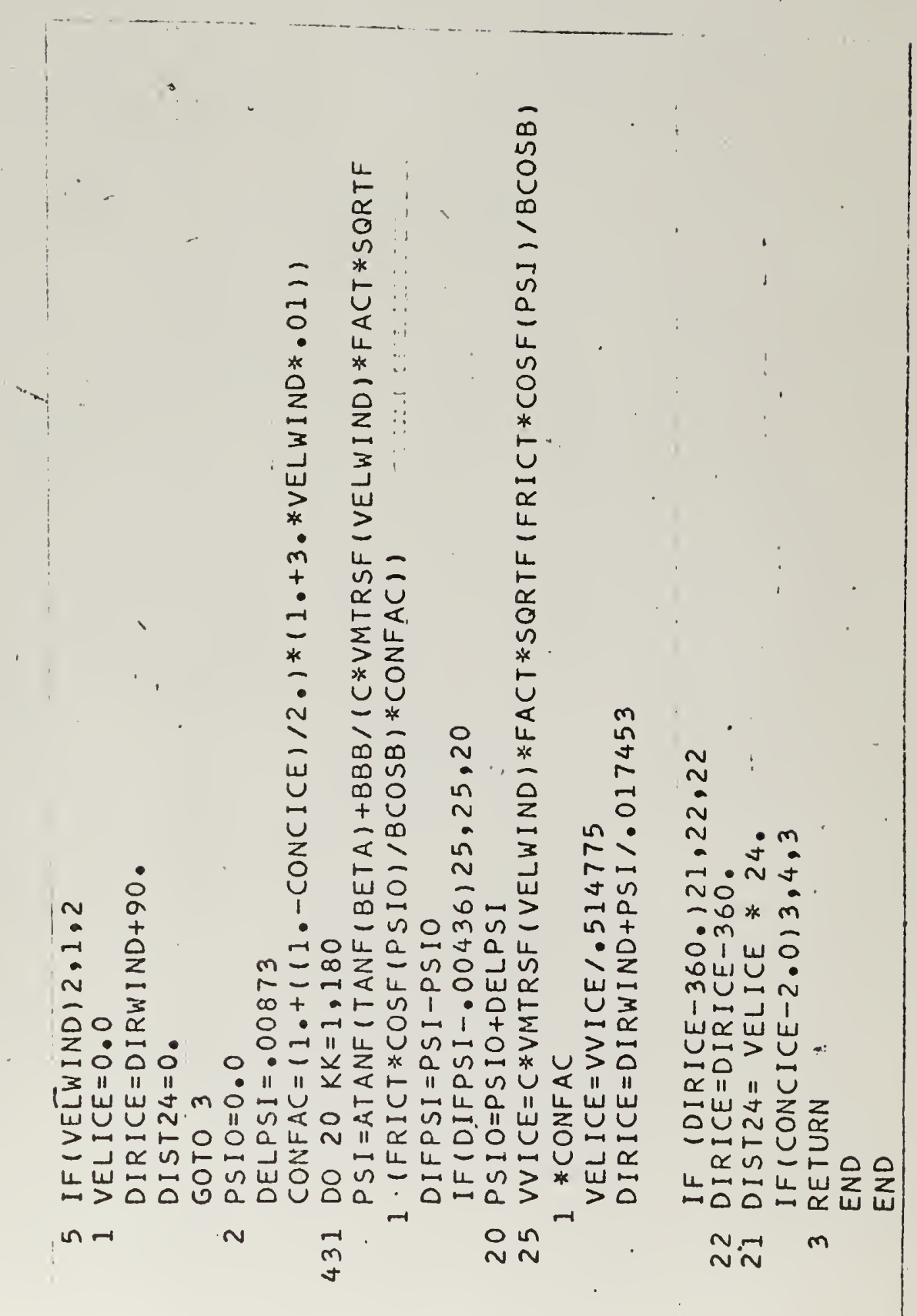








